Under-represented students' university trajectories: building alternative identities and forms of capital through digital improvisations

Dr Sue Timmis (corresponding author)

School of Education, University of Bristol,Bristol,UK. sue.timmis@bristol.ac.uk $+44(0) 1173314336$

orcid.org/0000-0001-8547-3576

Dr Bernardita Muñoz-Chereau

UCL Institute of Education, University College London, London, UK orcid.org/0000-0002-6387-8772 


\section{Under-represented students' university trajectories: building alternative identities and forms of capital through digital improvisations}

This paper focuses on widening participation in relation to under-represented student negotiations of and trajectories through university by drawing attention to students' informal digital practices for studying and social interactions associated with undergraduate student life. Drawing on a two-year UK study and Holland et al. (1998)'s framing of agency, culture and identity making across 'figured worlds', we consider the importance of informal studying and socio-academic practices and the role of digital technologies in fostering agency and identity making. The significance of this study lies in revealing the particular importance of improvisation and collective agency for under-represented students participating in university. Whilst acknowledging that technologies can also reproduce social inequalities, we conclude that, through the increasing interconnectedness of academic and social interactions, digital improvisations offer creative opportunities for students to negotiate spatial, social and academic inequalities and lead to new/alternative identities and develop stronger social, cultural and educational capital.

Keywords: widening participation, agency, digital cultures, social networks

\section{Introduction}

This paper focuses on under-represented, undergraduate students' own uses of digital technologies to support their studies outside of formal classes, their communications and social lives and how these practices can contribute to or constrain their academic endeavours, social and academic identities and sense of belonging. Widening participation and equity in higher education are a strong focus of policy, research and practice in many countries (Hinton-Smith 2012; Burke 2013) with an increasing emphasis on the in/equality of experience and outcomes once in university (McCulloch \& Thomas, 2013; Bathmaker et al, 2016). Yet informal practices and social interactions 
outside of formal educational spaces and the effects of these on under-represented students' participation and sense of belonging have received far less attention.

Under-representation ${ }^{1}$ in higher education is defined differently depending on country and context, but typically widening participation categories in the UK include students who are first generation into higher education, from lower socio-economic backgrounds, low participation neighbourhoods or low performing schools, those from black and minority ethnic communities, women, disabled students, care leavers, mature and local students and many of these categories are intersecting and groups should not be essentialised (Crozier, Burke \& Archer 2016). In this paper, we acknowledge these multiple and intersecting forms of diversity, which represent lived experience, rather than focusing on a single group or category. This interpretation is discussed later in relation to our study.

Moving from one context to another and negotiating transitions is always a matter of becoming, belonging and peer relationships. Meaningful interactions between staff and students foster 'a culture of belonging', and are seen as critical for retention and success (Thomas 2012,17). The transition to higher education can nevertheless be challenging for under-represented students who are often positioned as 'other' from their first day at university where they are required to 'fit in' to existing cultural norms (Read, Archer, and Leathwood 2003; Crozier, Reay, and Clayton 2010; Christie et al. 2016) and an 'institutional habitus' (Thomas 2002). This is augmented by managerialist concerns with student retention and success which tend towards deficit conceptions of students who need remedial help, rather than seeing where universities themselves might be in deficit (Christie et al. 2016). For Kahu and Nelson (2018), developing a

\footnotetext{
${ }^{1}$ The term 'under-representation' avoids a deficit positioning and moves away from a discourse of disadvantage.
} 
culture of belonging involves challenging existing positionings, rather than simply 'fitting in', which suggests transitions to and participation in higher education involve 'identity making' through changing understanding of self, in relation to individuals and social structures (Ecclestone, Biesta \& Hughes, 2010). Fataar $(2018,4)$ characterises this as a process of 'epistemic becoming' which he argues 'mostly occurs in peer networks on the margins of the university'.

Whilst Thomas (2012) highlights the relationship between peer interactions and well-being, retention and success, surprisingly little attention has been paid in the widening participation literature to informal social networks. In particular, despite the increasing influence of digital technologies in higher education, how under-represented students' interactions in digital spaces might influence cultures of belonging and participation is under-researched. Within university contexts, related research includes formal educational activities (e.g. Sánchez, Cortijo, and Javed 2013), preparations for university (DeAndrea et al., 2012), social interactions (e.g. Madge et al. 2009; Hamid et al. 2015) and technology-mediated transitions and boundary crossings (e.g. Author 1 and Williams 2016). However, research on the role of such practices specifically in the lives of under-represented groups within higher education is limited. Säljö (2010) argues that digital technologies can play a powerful role in maintaining social connections across space and time, opening up possibilities for new knowledge and modes of learning, which can challenge institutional systems and expand collective and individual capacities. Yet, their pervasiveness in university life can also be problematic or unhelpful (Selwyn 2016). Partly driven by worldwide acceptance of the hype, exaggerations and representation of technology as the solution to everything, universities may not recognise inequalities or the needs of under-represented groups, resulting in policies and practices that over generalise and homogenise students (Selwyn 
2014). Furthermore, online social networks can reinforce existing inequalities and marginalise particular groups (Hughes, 2009). A previous research study conducted in two Australian universities exploring the utility of digital technologies in relation to study practices, suggested that logistical and outcomes-focused uses were most prevalent, which strongly mirrored the systems and structures in place (Henderson, Selwyn, and Aston 2017). However, these findings suggest a clear demarcation between academic and social practices.

In the study reported in this paper, we start from the position that academic and social practices are intertwined, within and through the everyday lives of university students who come into multiple spaces of university, bringing rich and diverse backgrounds and prior experiences. We are interested in students' lived spaces, artefacts and practices and how transitions to and trajectories over time are constituted across multiple spaces (Leander, Phillips, and Taylor 2010). A trajectory implies a path or journey through a particular lifeworld and is often associated with becoming and changing identities (e.g. Barnett 1996). Transition suggests a complex process of multidimensional and multi-faceted change (Gale and Parker 2014), and a process of identity making, through changing understanding of self, others and social structures (Ecclestone, Biesta, and Hughes 2010). To interrogate how transitions and trajectories are negotiated within and through university spaces, we employ the conceptual framing of figured worlds, identity, agency and improvisations (Holland et al. 1998). Specifically, a previous research study conducted in two Australian universities exploring the utility of digital technologies in relation to study practices, suggested that logistical and outcomes-focused uses were most prevalent, which strongly mirrored how digital improvisations can help to overcome existing positionings and their influence on changing identities, academic progress and sense of belonging. In the following section, 
we discuss our understanding of identity, agency and digital improvisations before introducing the study on which the paper is based and the findings related to this topic.

\section{Identity, Agency and Figured Worlds}

The proliferation of conflicting theories of identity has contributed to its ambiguous definition (Adams 2006). On the one hand, more individuated, self-reflexive positionings (for example Giddens 1991) and on the other, more structurally bounded, constrained and unconscious interpretations, principally drawing on habitus (Bourdieu 1977) to frame the debate. However, neither of these schools of thought has dealt adequately with the tension between an overly agentive and an excessively structurecentric understanding of identity. Therefore, the need for the hybridization of these positions, where structure and agency both contribute to a social conceptualisation of identity is needed (Adams 2006).

A hybrid interpretation of identity and agency in cultural worlds, proposed by anthropologist Dorothy Holland and colleagues (1998) does precisely this, by incorporating reflexivity and agency and acknowledging the societal structuring and positionings that shape us. Drawing on theories from Bourdieu, Vygotsky and Bakhtin, they propose the construct of a figured world which is 'a socially and culturally constructed realm of interpretation in which particular characters and actors are recognized, significance is assigned to certain acts, and particular outcomes are valued over others' (Holland et al. 1998, 52). They are socially organised encounters, located at a particular time and place. A university, a social group or an online network, for example, can all be considered as figured worlds. Through our encounters with different figured worlds over time, we gain new or changing identities 'through continued participation in the positions defined by the social organisation of those 
worlds' activity'(Holland et al. 1998, 41). Therefore, how we act when encountering new figured worlds gives rise to and shapes our identities. Instead of seeing identity in essentialist terms, we consider it as 'self in practice' (Holland et al. 1998, 31). This means that agency is always social and relational (Edwards 2005). It is through using our agency to improvise that we can move beyond the social positioning and structures that reproduce inequalities, and overcome the cultural and historical constraints that powerful structures and positions embody. This conception of improvisation can also be defined as the interplay between agency and habitus.

\footnotetext{
'Improvisations are the sort of impromptu actions that occur when our past, brought to the present as habitus, meets with a particular combination of circumstances and conditions for which we have no set response. Such improvisations are the openings by which change comes about from generation to generation.' (Holland et al., 1998, pp. 17 -18)
}

Thus, identities are always dynamically co-produced cultural phenomena whose meanings change over time (Urrieta 2007). Figured identities provide individuals with the opportunity to challenge positional identities through new imaginaries and develop reformed subjectivities from the available cultural resources (Holland and Lachicotte 2007).

\section{Digital Improvisations}

The sociocultural tradition foregrounds the mediational role of the material within practices: the technological, the bodily and affective, and time and space constituted as part of the social, cultural and historical context (Vygotsky and Kozulin 1986; Daniels 2015). Technologies can also represent possible forms of objectified cultural capital, which expand opportunities (Czerniewicz and Brown 2012). Similarly, Holland et al (1998) refer to artefacts and tools as cultural pivots into new worlds, which can open up 
new imaginaries and possibilities within a figured world. They act simultaneously as 'both instrument and collective remembrance' (Holland et al. 1998, 61). This is particularly relevant for understanding under-represented students' transitions from other worlds and trajectories through both the online and physical worlds of higher education.

In summary, identities can be understood as the 'self in practice' (Holland et al. 1998, 31). Through improvisations and alternative imaginings, students use their agency to make and remake their identities, moving beyond the institutional and social positionings they face within a figured world or as they transition to another. Digital technologies can create places, mobilities and possibilities through which improvisations and identity making can occur, contributing to new positionings across the intersecting figured worlds of higher education. Through the possibilities for establishing group spaces and communications across spaces, we argue that digital technologies can act as cultural pivots to open up new socio-academic spaces, discourses, collective forms of agency and capital. We employ the notion of digital improvisations to articulate how actors individually and collectively employ agency and digital artefacts as cultural pivots and mechanisms for identity making and problemsolving. Yet, in some contexts 'digital capital' may not be enough to feel a sense of belonging (Seale 2012). Digital artefacts (for example online networks) may also contribute to reproducing social or historical positionings that under-represented students encounter at university or the reproduction of inequalities or exclusion (Hughes, 2009). Therefore we take a multi-dimensional and critical perspective to explore digital improvisations and their possibilities. 


\section{The DD-lab Study}

This study investigated under-represented undergraduate student experiences and relationships with peers over the course of one and half academic years at a UK research-intensive university, known here as UKU. It investigated digitally-mediated studying practices, particularly informal interactions with peers, outside of formal classes. We defined under-representation firstly, as first generation at university and non-fee-paying school attendance. We further stratified the sample through intersections with three under-represented groups: black and ethnic minority, mature and 'local'² students. Whilst acknowledging that social class can shape experience and identity in universities (e.g. Bathmaker, Ingram, and Waller 2013), we aimed for an intersectional sample by including other indicators of under-representation such as age, ethnicity and locality, all of which afford social positioning (Hodkinson, Biesta, and James 2008). By combining multiple, widening participation indicators, we examined a wide range of social, cultural and spatial dimensions to understand the multifaceted, lived experience of under-representation.

Thirty-one $2^{\text {nd }}$ year undergraduates took part in the study during academic years 2013 -15. Students were recruited as volunteers through a short survey to all secondyear students. Students came from 22 programmes across six faculties, including subjects as varied as medicine, social policy, classics, history and civil engineering. As shown in table 1 below, the final sample included 17 women, 14 men, 11 mature, 11 students from black and minority ethnic backgrounds (BAME), seven who were local and 14 who were campus-based (university halls or shared student accommodation).

\footnotetext{
${ }^{2}$ Our interpretation of 'local' was broader than that of UKU, which only focuses on two (neighbouring) postcode groups. We felt this was too narrow and included those students within travelling distance and who were commuting in (the furthest was 70 miles away).
} 
Table 1 about here

By taking an intersectional approach, we were not seeking to compare students' experiences, in relation to specific categories or groups. McCall (2005) suggests that intersectional methods are often closely linked to narrative methods (discussed below), where data are drawn principally from narrative accounts (documentaries) and interviews. Such analyses have limitations, including acknowledging that personal narratives cannot represent or situate individual accounts within the full network of relationships and can only offer a partial perspective of the particular social group (McCall 2005). We fully acknowledge this in our study, by recognising that although the 31 participants offered rich and diverse accounts, they are partial representations of the multiple groups to which they belong. Furthermore, elsewhere, we have focused more on the experiences of a particular group, i.e. Mature students (see Author 2 and Author 1 in press), but that is not the aim of this paper.

A participatory, co-researcher methodology (Author 1, 2012; Author 1 \& Williams, 2013) was implemented, which aimed to avoid a deficit positioning of underrepresented students, by supporting students to participate as co-researchers to research their own learning experiences over time, through longitudinal involvement (12 months). Co-researchers were given an iPad and used it to document their learning lives. They had a central role in the research and opportunities to shape it, emphasising their voices and experiences, and crucially, deciding over the data they contributed (Author 1 et al., 2016). However, participatory research may not mean participation in every aspect of research (Heron and Reason 2001). There were also time constraints and ethical issues in relation to the data of other co-researchers. Nonetheless, co-researchers contributed to preliminary analysis, conference presentations and blog postings on the website. Overall co-researchers created 637 multimodal documentaries of their informal 
studying practices and the use of digital technologies within their learning lives across three month-long stages (November, February/March, May) during the first academic year using the application Evernote ${ }^{3}$. The multimodal data collected included text accounts, audio, video, photos, snapshots from screen or documents and annotated notes. Individual interviews and focus groups were conducted after each documentary creation stage including a final interview in their third year, reviewing the second year. In summary, whilst not involved in every aspect of the research process, the coresearchers were researching their own learning lives longitudinally, and gaining research experience and expertise throughout. Their level of commitment to this process was also demonstrated by the lack of attrition (thirty one from an original thirty two students remained in the study).

Research questions explored the extent to which 'a culture of belonging' and engagement were experienced by under-represented students, informal support and peer relationships and the role of digital technologies for constraining or supporting underrepresented students' educational, cultural and social purposes. Nvivo10 was used to manipulate textual and multimodal analyses, following our analytic frame. After transcription, data was thematically coded (interviews, focus groups transcripts and Evernote multimodal artefacts), paying close attention to relationships across data collection phases and data types.

Four main themes were identified: widening participation, belonging and identities, use of digital media and lived experience. We examined multi-dimensional relationships between the main themes and sub-themes, for example, how digital media helped or hindered direct-entrant students' sense of belonging and participation and in

\footnotetext{
${ }^{3}$ Evernote allows users to capture, organise, and share notes, including video, photographs and audio files and synchronise between devices. See http://www.evernote.com
} 
relation to our theoretical constructs. The focus of this paper is on how students were using digital technologies to adapt to or resist these challenges and how the digital expectations of the university shapes students' experiences and influenced their positionings and identities in the figured worlds they encountered.

\section{Digital improvisations}

Co-researchers documented their learning lives throughout a 12-month period and across two academic years. In particular, they focused on the ways in which digital technologies mediated their academic studies, social interactions and sense of belonging to the university. They were asked to reflect on what digital practices enabled them to do differently but also the digital inequalities, constraints and challenges they faced. All co-researchers engaged in a wide variety of digital practices and digital improvisations and there was a strong emphasis in documentaries on initiating action with technology in order to make changes and challenge existing positionings and identities.

\section{Negotiating studying across lived spaces}

Co-researchers highlighted how their learning was situated across multiple, lived digital and physical spaces, where they needed to negotiate studying alongside part-time work (many had more than one part-time role), family and caring responsibilities, social lives and (for some) living long distances away. Studying took place across the day (and night), variously mediated by digital technologies, often working with other students. They gave many examples of devising new ways of working to expand their academic capital, for example, combining and augmenting information selected from different sources and creating new visual representations of knowledge. Many of these digital improvisations produced or co-produced, shared artefacts. Some co-researchers commented that having an iPad had itself mediated and expanded their studying 
practices, enabling them to work multi-spatially, including at the gym, cafes, on the train, in library and during lectures as the iPad was more portable than a laptop:

...my laptop itself is quite chunky and so being able to go to the library and only having to carry an iPad instead of my laptop in conjunction with all my books is really useful, as often my bag was excessively heavy. (Female, direct entrant, Civil Engineering)

In line with Czerniewicz and Brown (2012) the embodied, cultural capital of the iPad expanded opportunities for negotiating new studying practices across the multiple spaces and demands of university life.

Whilst the majority of co-researchers were reflexive about their own improvisations for studying, they also highlighted challenges from juggling competing demands derived from part-time working, family commitments and long distance travel. Using technologies to improvise different ways of overcoming time/space inequalities was critical. Students doing part-time jobs reported how they continued to participate in academic discussions and social events remotely, whilst at work using social media. Thus, they could be away from the university, but could still be present and maintain their social and academic identities alongside their paid work roles. However, there were some co-researchers who faced multiple, competing time/space demands (for example combining single parenthood, part-time work and university deadlines). They tended to be more isolated and struggled to overcome the extensive challenges faced, expressing feelings of stress and powerlessness. Thus, whilst social media can help to negotiate different time/space configurations, these improvisations are not the solution to everything for everyone. Some inequalities, particularly when they are intersecting, were not easily overcome. 


\section{Socio-academic identities}

When discussing their university lives, co-researchers emphasised the importance of their interactions with others (peers, tutors, friends, family members etc.) physically and online. Facebook was the most commonly used communication mode within the university, with friends on their course, societies, and where they lived. On Facebook, social and academic conversations were completely intertwined. It was the space where many co-researchers (particularly direct entrants) went first to check on what was happening or to ask questions and often for emotional support:

So yeah I don't do that much work, actual work on Facebook but it's more like the work support group so it's when the work has become too much (Female, direct entrant, Psychology)

Not all university relationships were so easily mediated by social media, which can also reproduce inequalities. One mature co-researcher expressed reservations about being on Facebook with much younger, fellow students:

she [a classmate] friended me on Facebook and I didn't know what to do because I thought this is a weird relationship - you know a 60 year old and an 18 year old it's weird (Female, over 21, Social Policy and Politics)

She felt positioned differently to her younger counterparts within the online space and socially awkward, although over time, her documentary showed that this relationship developed through face-to-face interactions.

Online social networks associated with societies or extra curricular activities enabled co-researchers to situate themselves in a world within the university world, with its own positionings and to develop a sense of belonging and identity to a different aspect of university life: 
Club captain...this is a role that I love... what was sold to me as a great $\mathrm{cv}$ booster... I have a committee Facebook group set up where we discuss various things and there are a lot of emails! (Male, Over 21, Biochemistry)

His role as club captain helped him develop an emergent leadership identity and new forms of social capital, facilitated by establishing a social media presence through Facebook and digital communications. Another example below, again shows that belonging is mediated by digital communications but not necessarily to 'the university' or even to academic groups:

'in terms of the sense of belonging, I'm not sure whether I, like, feel part of Bristol, but I guess digital communications... Like, the Feminist Society, we have, like, a massive Facebook group which is, like, huge.....that's a kind of example of how I feel like I belong to something, which is also quite closely linked to online communication' (Female, over 21, Social Policy)

Developing a sense of belonging through digital improvisations was therefore, not necessarily restricted to the academic dimension of university life, but often involved extra curricular activities that reflected their wider interests and helped them expanding their friendships, involvement and participation.

For those students living away from home, connections to family and friends were regularly mediated through digital communications and online social networks, which helped to ease the transition to university through maintaining existing identities:

I think I talked to my friends quite a lot when I first got here - like, friends from home who I went to college with - and we had... Cos they were all asking, 'How's university?' and I was saying there's so many strange people it's like a totally different planet. (Female, over 21, Social Policy)

I ring my mum every day. I try to speak to my brother every day. I don't know how ... I probably speak to my dad a couple of times a week. (Male, direct entrant, Dentistry) 
Many of the co-researchers relied heavily on regular family support and intensive communications. The quote below is another example of the importance of family and friends from home and building alternative networks whilst at university.

My brother and I both decided to make an Instagram page dedicated to our gym antics....it has proved a massive help in getting connected with others in the fitness world $\&$ also helps in my own understanding of the science behind the fitness (Female, Direct entrant, History)

Therefore, digital platforms can act as cultural pivots into a different world where new identities, and alternative forms of social capital may be imagined and realised (Holland et al. 1998).

\section{Collaborative improvisations}

Co-researchers discussed the different phases of becoming and belonging to university. The findings suggest that whilst in year one there was more social experimentation (by for example initiating new social encounters with classmates), in the second year, they were falling back on who they were in terms of background and where they came from. Social differences appeared even more noticeable than at the beginning. The third year was described by one co-researcher as an 'intellectual awakening' in the sense that peers were more willing to share ideas, discuss and work, and took active part in digital networks to support collaboration. The role of digital technologies in supporting collaborative work also seemed to develop more from the second year onwards, in the sense that the digital practices tended to built on top of their friendship and peer groups, but not the other way round.

Text message help between course mates.... Very common for me. I get asked about stuff, and ask things of friends myself. I would say we've become quite good at effectively talking about engineering by short texts! (Male, direct entrant, Civil Engineering) 
As argued previously, improvisations are social practices and involve relational agency and problem-solving to overcome historical positionings and build alternative identities and forms of academic and social capital (Holland et al. 1998; Edwards 2005). Coresearchers highlighted many examples where collaboration through digital technologies and social media enabled them to overcome academic and social challenges, especially managing time/space complexities and working on assignments:

\footnotetext{
"We collaborate over the internet which is great (...) So we'll have assignments and stuff, and we'll be like: 'I can do this bit, but I can't actually do this bit'. Someone else'll be like: 'Oh, I can't do that bit but I can do the other bit that you can't do'. So we'll all work together on things like that" (Female, direct entrant, Cancer Biology)
}

'This works well for me as [friend] has downloaded a .chm of Wheaters text book. We put this in front to help and [other friend] took pictures on his phone and Whatsapp'd them to us so we can add our own annotations when we get home.' (Female, over 21, Medicine)

They also used social networks to resolve wider problems that would be difficult to do face-to-face, as shown in this example concerning library books:

Last week while writing coursework essays we had a bit of an issue regarding library books (loads of people needed the same selection) so we used the fb page to organise a sort of rota (Female, direct entrant, Psychology)

These collaborative improvisations show how under-represented students were negotiating the challenges of university spaces and systems, some of which was particularly problematic for those whose backgrounds and circumstances are more complex but who are nonetheless expected to 'fit in' (Kahu and Nelson 2018). They helped to expand their collective forms of academic and social capital and build stronger academic identities through challenging institutional habitus (Thomas 2002). 
Furthermore, some co-researchers reported they were systematically mobilising social networks and file sharing 'apps'(applications) such as Dropbox. These informal group spaces worked in parallel to the formal work of the programme or course, offering alternative, socio-academic spaces which students established and controlled (unlike institutional environments) with their own positionings, artefacts and discourses. Such spaces were designed for questions, informal discussions, sharing notes and lecture recordings widely throughout the cohort and were mostly unofficial and unseen by academics. Co-researchers highlighted that such spaces allowed them to ask 'dumb' questions that they would not have the confidence to ask the lecturer or in a physical face-to-face setting such as a lecture theatre. Many co-researchers' documentaries reported that they often felt unable to ask questions in lectures, especially earlier in their university lives, when they became aware of differences between levels of prior experience in the cohorts. Setting up peer-led spaces allowed for alternative positionings and expanded social and academic capital.

Unofficial recording of lectures was another common practice and largely hidden from academic staff. By recording and sharing the artefacts, checking them later or consulting online sources immediately during class, they could keep up with lectures.

\footnotetext{
My friend and I have set up a shared folder in Dropbox so if either of us miss a lecture or I'm late because of the train, or as what happened today my dictaphone ran out of space we can get the lectures off each other. ...the dictaphone lets me relax a little and not worry about getting everything down. Instead I can concentrate [on] making notes in my own words, making sure I understand rather than scribing. (Female, over 21, Medicine)
}

Co-researchers also documented how they sought online validation during lectures of things they didn't understand. 'Apps' downloaded onto phones, iPads, or laptops allowed them to determine what kinds of support they might need. Online 
sources of alternative academic expertise (for example YouTube tutorials and forums) supplemented lectures where they didn't understand some aspects of their teaching. Online mentoring from friends and family was also a key feature of documentaries. As shown in Figure 1, this co-researcher used Skype to talk every day to her friend from home who was studying elsewhere. Her friend was further on in her university studies and acted as a mentor and collaborator. Other co-researchers documented similar occurrences with friends and family members, although usually less formalized.

Figure 1 here

Figure 1 - Extract from Evernote documentary showing a Skype mentoring conversation.

These 'hidden', yet collaborative improvisations supplemented official curricula and teaching within the university world, and helped them to overcome deficit positionings and shape new literacies. Whilst these practices were not unique to those from under-represented backgrounds, co-researchers felt they were critical to developing their confidence, and expansion of academic capital, enabling them to participate more equally and to develop their own distinctive, academic identities.

\section{Digital conformities and inequalities}

Reliance on digital technologies also brought downsides. Co-researchers stressed campus life, engaging with tutors or meeting with peers informally were key facets of university that were in danger of disappearing in an increasingly digital university environment. Co-researchers emphasised their dependency on technological devices and the Internet to function well at university. This was a constant and uncomfortable feeling for some, especially when something went wrong (i.e. internet access or laptop failure) partly because of the financial impacts, but also because of the constant necessity of being digitally connected and expectations of the increasingly digitalized 
university (Selwyn 2014). There were tensions between the formal university systems and those used by them in their daily lives to support their informal learning and studying practices which can make it harder to engage (Author 1, 2012). For many coresearchers, accessing newer devices felt out-of-reach from a financial point of view. They found the need for constant updating, replacing laptops or paying for premium versions (with extended capabilities) and the status attached to the 'latest' device were sources of anxiety and financial costs. Many were making do with old laptops and out of date applications, which had implications for their studies. These inequalities were more difficult to improvise.

Interactions on social media also tended to be concentrated within established social groups and communities where social and academic conversations were interwoven. These socio-academic spaces could be exclusionary for some mature students and those who didn't want to be part of Facebook or the 'party' culture of university life, but did want to engage in academic discussions with peers on the courses. The increasing social and academic connectedness through social media gives rise to a new kind of conformity, which excludes those who were not willing or able to adopt such practices or work across social and academic boundaries. This is exacerbated by the fast pace of change in social media 'fashions' and digital practices, which doesn't suit everyone. Some co-researchers reported that they could contribute their ideas and opinions more easily in online environments, without being intimidated by more dominant characters or being positioned in particular ways. One co-researcher, a BAME student, reported that she felt less judged in online discussions than in face-to-face encounters, in a predominantly white university environment and therefore more willing to contribute her opinions. There were, however, several co-researchers who made a choice to stay away from social media altogether, for social or religious reasons. 
Interestingly, only one co-researcher mentioned any concerns over online bullying, discrimination or privacy. This co-researcher (a mature, BAME student studying Medicine) highlighted unwanted, unsavoury attention online and that consequently, she was careful with what she posted on social media. Our data was collected prior to recent privacy and surveillance scandals in 2017-18 connected to social media sites and Facebook in particular, including the proliferation in data harvesting from digital footprints and emerging inequalities (Micheli, Lutz, and Büchi 2018). The limited comments on this issue may be partly because we did not ask co-researchers directly about such practices and concerns. However, this silence in our data perhaps also reflect the previously, limited discussions in universities over ethics and privacy issues concerning the use of personal data in higher education, learning analytics and reproduction of inequalities (Prinsloo and Slade 2016). These issues warrant further research.

\section{Discussion}

Co-researcher documentaries included numerous examples of the creative possibilities of working collaboratively or individually to (re)construct their own digital resources, support mechanisms and modes of working in alternative academic spaces and using digital technologies to negotiate the diverse and intersecting lived spaces of being a higher education student. Digital improvisations involving reconfiguring time/space opportunities also helped to overcome some of the spatial inequalities experienced by students from more complex, under-represented backgrounds with competing demands on their lives. Digital improvisations gave them the agency and the means to negotiate new mobilities and reconcile their multiple identities and roles across different worlds (Leander, Phillips, and Taylor 2010; Holland et al. 1998). Informal interactions and 
engagements with peers, as much as formal class activities, were critical to developing an academic identity and sense of belonging,. Such improvisations reveal some of the ways in which under-represented students negotiate the transition to and trajectories through the figured worlds of university, developing socio-academic identities that address positionality and uncertainty (Holland et al., 1998). Reaching into different cultural worlds may help to sustain students whose academic identities need reinforcing (Crozier et al., 2010) and whilst not exclusive, this is more critical for students from more diverse backgrounds who are often positioned by universities as in deficit (Christie et al. 2016).

Developing a sense of belonging and academic identity involves challenging existing positionings (Kahu and Nelson 2018). We have shown how co-researchers employed agency and artefacts to resist institutional and existing social positionings and overcome associated challenges by creating new possibilities and ways of becoming (Holland et al. 1998; Urrieta 2007). We argue that their digital improvisations offered opportunities for new identities, in particular through establishing hybrid, socioacademic online spaces that students themselves established and sustained, developing their own practices and literacies.

Nevertheless, some inequalities were harder to resolve, especially as digital technologies in higher education must also be seen as 'a function of broader processes of social reproduction' (Smith, Skbris, and Western 2013, 115). The constant need for technological updating, in order to function in the increasingly digital university environment, caused anxieties and limitations on some co-researchers' work. These technocratic requirements disadvantage students from under-represented backgrounds, without the same economic capital as other students (Czerniewicz and Brown 2012). 
Co-researchers in our study were mainly very positive about the influence of social media and online working and apart from one student, they did not explicitly highlight issues of surveillance or privacy in relation to social networks such as Facebook. Nevertheless, they were not universally accepted as positive spaces either and the inequalities and issues concerning surveillance and privacy in online social networks are growing (Micheli, Lutz, and Büchi 2018), which suggests that more caution is needed in advocating the use of social media in higher education. Students need to become more aware of privacy, surveillance and ethical issues concerning networks and data (Prinsloo and Slade 2016).

Online social networks often reproduce existing inequalities (Boyd 2011; Hughes 2009) and we provide examples where students from different ages or religious backgrounds, chose not to or were not included in the collaborative online spaces and social networks. Paradoxically then, the stronger the intertwining of social and academic lives for many students, the more challenging and potentially disenfranchising this can be for those who are excluded. We should therefore be mindful to avoid universalising the relationship between participation in digital figured worlds, and belonging.

Furthermore, to what extent do digital improvisations only focus on narrow instrumental actions, such as getting assignments finished? In what ways do they break down barriers for under-represented students or foster social connections? Our findings have shown that the interconnectedness of social and academic interactions is critical and one the most valuable aspects of the digital improvisations and lived spaces established by co-researchers. Whilst it was not always clear whether students had become friends through these interactions, many social interactions took place alongside academic work and they collaborated with students from diverse backgrounds. Social 
and academic interactions were mutually constituted as part of the socio-culturally lived experience of university life (Leander, Phillips, and Taylor 2010; Daniels 2015; Holland and Lave 2009). As Fataar $(2018,2)$ suggests, for under-represented students to negotiate university, they must 'establish a platform for their epistemic becoming' giving meaning to 'spaces of possibles'. He also suggests that peers are crucial in relation to developing a sense of belonging and to students' academic struggles. We are not suggesting that digital improvisations, such as those found in this study are sufficient in themselves to break down social barriers and inequalities, and we acknowledge that digital spaces too, can be exclusionary. However, we argue that digital improvisations allow under-represented students to employ their own agency and open up socio-academic spaces of possibilities to address some of the challenges of 'epistemic becoming'(Fataar 2018) and thereby become the authors of alternative socioacademic identities and positionings.

\section{Conclusions}

We have shown the importance of improvisation, individual and collective agency for under-represented students' successful university trajectories and how the increasing interconnectedness of academic and social interactions in a digital world gives rise to powerful opportunities for digital improvisations and creative problem solving. Yet we recognise that as universities become increasingly digital, this places new demands on all students including continuing financial costs, awareness of surveillance and privacy issues and new cultural expectations, which might place additional burdens on students from under-represented backgrounds.

Our research was conducted across one university, yet the findings echo recent literature in showing that university support for students from widening participation 
backgrounds is mainly institution-led, not student-led. Whilst acknowledging that digital improvisations do not necessarily lead to equality or inclusion, in this study, the intertwining of informal studying practices and the social sides of university life with digital improvisations in online spaces offered an alternative perspective to the topdown support which can position under-represented students as needy and in deficit. By contrast, we have shown how under-represented students exercised agency, often collectively, to overcome institutional positionings, social, academic and spatial inequalities, which can lead to new or alternative identities and expanded social, cultural and educational capital. This suggests that rather than adopting a deficit lens, universities should seek to understand and acknowledge the role of student agency, socio-academic practices and online and offline lived experiences in mediating successful university trajectories.

\section{Acknowledgements}

We wish to thank the 31 co-researchers who took part in the [removed] study for their inspiration and invaluable contributions to this work. Many thanks are also due to Professor Sheila Trahar and the anonymous reviewers for their insightful and helpful comments on an earlier draft of this paper.

\section{Funding}

This work was supported by [university name removed] Widening Participation Research Fund.

\section{Word count : 6665 excluding references}




\section{References}

Author 2 \& Author 1 (2019 in press) Making mature undergraduates' experience visible: exploring sense of belonging and use of digital technologies. Journal of Widening Participation and Lifelong Learning.

Author 1.and J. Williams. 2016. Transitioning across networked, workplace and educational boundaries: chronotopic movements and cultural adaptations. In $\mathrm{M}$ de Laat, T. Ryberg, S. Bayne, C. Sinclair. (Eds) The design, experience and practice of networked learning. Research in Networked Learning, Springer, New York.

Author 1., W. Yee. and E. Bent. 2016. Digital Diversity and Belonging in Higher Education: A Social Justice Proposition. In E.L. Brown, A.Krasteva, M. Ranieri, (Eds) International Advances in Education: Global Initiatives for Equity and Social Justice, Volume 10. E-learning \& Social Media: Education and Citizenship for the Digital 21 st Century. Information Age Publishing, Charlotte, N.C.

Author 1. and J. Williams. 2013. Students as co-researchers: a collaborative, community-based approach to the research and practice of technology enhanced learning. In E. Dunne \& D. Owen (Eds.), The Student Engagement Handbook, Practice in Higher Education (pp. 509 -525). Bingley, UK: Emerald.

Author 1. 2012. Constant Companions: Instant Messaging Conversations as Sustainable Supportive Study Structures amongst Undergraduate Peers. Computers \& Education, 59 (1), 3-18. Retrieved from http://dx.doi.org/10.1016/j.compedu.2011.09.026

Adams, Matthew. 2006. 'Hybridizing Habitus and Reflexivity: Towards an Understanding of Contemporary Identity?' Sociology 40 (3): 511-28. https://doi.org/10.1177/003803850663672.

Barnett, Ronald. 1996. 'Being and Becoming: A Student Trajectory'. International Journal of Lifelong Education 15 (2): 72-84.

Bathmaker, Ann-Marie, Nicola Ingram, Jessica Abrahams, Anthony Hoare, Richard Waller, and Harriet Bradley. 2016. Higher Education, Social Class and Social Mobility: The Degree Generation. London: Palgrave Macmillan. https://doi.org/10.1057/978-1-137-53481-1.

Bathmaker, Ann-Marie, Nicola Ingram, and Richard Waller. 2013. 'Higher Education, 
Social Class and the Mobilisation of Capitals: Recognising and Playing the Game'. British Journal of Sociology of Education 34 (5-06): 723-43.

https://doi.org/10.1080/01425692.2013.816041.

Bourdieu, P. 1977. Outline of a Theory of Practice. Cambridge, U.K: Cambridge University Press.

Boyd, Danah M. 2011. 'White Flight in Networked Publics? How Race and Class Shaped American Teen Engagement with MySpace and Facebook'. In Race After the Internet, edited by L Nakamura and P Chow-White, 203-22. New York: Routledge.

Burke, Penny Jane. 2013. The Right to Higher Education: Beyond Widening Participation. Abingdon, Oxon: Routledge.

Christie, Hazel, Lyn Tett, Viviene E. Cree, and Velda McCune. 2016. “'It All Just Clicked": A Longitudinal Perspective on Transitions within University'. Studies in Higher Education 41 (3): 478-90. https://doi.org/10.1080/03075079.2014.942271. Crozier, Gill, Penny Jane Burke, and Louise Archer. 2016. 'Peer Relations in Higher Education: Raced, Classed and Gendered Constructions and Othering'. Whiteness and Education 1 (1): 39-53. https://doi.org/10.1080/23793406.2016.1164746.

Crozier, Gill, Diane Reay, and J Clayton. 2010. 'The Socio-Cultural and Learning Experiences of Working Class Students in Higher Education'. In Improving Learning by Widening Participation in Higher Education, edited by M David, 6274. London: Routledge.

Czerniewicz, L, and C Brown. 2012. 'Objectified Cultural Capital and the Tale of Two Students'. In Exploring the Theory, Pedagogy and Practice of Networked Learning, edited by L Dirckinck-Holmfeld, V Hodgson, and D McConnell, 209- 
19. New York: Springer.

Daniels, H. 2015. 'Mediation: An Expansion of the Socio-Cultural Gaze'. History of the Human Sciences 28 (2): 34-50. https://doi.org/10.1177/0952695114559994.

DeAndrea, David C., Nicole B. Ellison, Robert Larose, Charles Steinfield, and Andrew Fiore. 2012. 'Serious Social Media: On the Use of Social Media for Improving Students' Adjustment to College'. Internet and Higher Education 15 (1): 15-23. https://doi.org/10.1016/j.iheduc.2011.05.009.

Ecclestone, K, G Biesta, and M Hughes. 2010. Transitions and Learning through the Lifecourse. Abingdon, Oxfordshire: Routledge.

Edwards, Anne. 2005. 'Relational Agency: Learning to Be a Resourceful Practitioner'. International Journal of Educational Research 43 (3): 168-82. https://doi.org/10.1016/j.ijer.2006.06.010.

Fataar, A. 2018. 'From the Shadows to the University's Epistemic Centre: Engaging the (Mis)Recognition Struggles of Students at the Post Apartheid University'. In Higher Education Close Up 2018. Cape Town, South Africa: University of Cape Town.

Gale, Trevor, and Stephen Parker. 2014. 'Navigating Change: A Typology of Student Transition in Higher Education'. Studies in Higher Education 39 (5): 734-53. https://doi.org/10.1080/03075079.2012.721351.

Giddens, A. 1991. Modernity and Self Identity:Self and Society in the Late Modern Age. Cambridge, U.K: Polity Press.

Hamid, S., J. Waycott, S. , Kurnia, and S. Chang. 2015. 'Understanding Students' Perceptions of the Benefits of Online Social Networking Use for Teaching and Learning'. The Internet and Higher Education, 26: 1-9. 
Henderson, Michael, Neil Selwyn, and Rachel Aston. 2017. 'What Works and Why? Student Perceptions of "Useful” Digital Technology in University Teaching and Learning'. Studies in Higher Education 42 (8): 1567-79.

https://doi.org/10.1080/03075079.2015.1007946.

Heron, J, and P Reason. 2001. 'The Practice of Co-Operative Inquiry: Research With Rather Than On People'. In Handbook of Action Research: Participative Inquiry and Practice, edited by P Reason and H Bradbury, 179-88. London: Sage Publications.

Hinton-Smith, T. 2012. Widening Participation in Higher Education: Casting the Net Wide? Issues in Higher Education. London: Palgrave Macmillan.

Hodkinson, Phil, Gert Biesta, and David James. 2008. 'Understanding Learning Culturally: Overcoming the Dualism between Social and Individual Views of Learning'. Vocations and Learning 1 (1): 27-47. https://doi.org/10.1007/s12186007-9001-y.

Holland, D, and W Lachicotte. 2007. 'Vygotsky, Mead, and the New Sociocultural Studies of Identity.' In The Cambridge Companion to Vygotsky, edited by $\mathrm{H}$ Daniels, M Cole, and J V Wertsch, 101-135. Cambridge, U.K: Cambridge University Press.

Holland, D, W Lachicotte, D Skinner, and C Cain. 1998. Identity and Agency in Cultural Worlds. Cambridge, Massachusetts: Harvard University Press.

Holland, D, and J Lave. 2009. 'Social Practice Theory and the Historical Production of Persons'. Actio: An International Journal of Human Activity Theory, no. 2: 1-15. Hughes, G. 2009. 'Social Software: New Opportunities for Challenging Social Inequalities in Learning?' Learning, Media and Technology 34 (4): 291-305. 
Kahu, E.R, and K Nelson. 2018. 'Student Engagement in the Educational Interface: Understanding the Mechanisms of Student Success.' Higher Education Research \& Development 37 (1): 58-71.

Leander, Kevin M, Nathan C Phillips, and Katherine Headrick Taylor. 2010. 'The Changing Social Spaces of Learning: Mapping New Mobilities'. Review of Research in Education 34 (1): 329-94.

https://doi.org/10.3102/0091732X09358129.

Madge, C, J Meek, J Wellens, and T. Hooley. 2009. 'Facebook, Social Integration and Informal Learning at University: It Is More for Socializing and Talking to Friends about Work than for Actually Doing Work'. Learning, Media and Technology 34 (2): $141-55$.

McCall, Leslie. 2005. 'The Complexity of Intersectionality'. Signs 30 (3): 1771-1800. https://doi.org/10.1086/426800.

McCulloch, A, and Liz Thomas. 2013. 'Widening Participation to Doctoral Education and Research Degrees: A Research Agenda for an Emerging Policy Issue.' Higher Education Research \& Development 32 (2): 214-27.

Micheli, Marina, Christoph Lutz, and Moritz Büchi. 2018. 'Digital Footprints: An Emerging Dimension of Digital Inequality'. Journal of Information, Communication and Ethics in Society 16 (3): 242-51. https://doi.org/10.1108/JICES-02-2018-0014.

Prinsloo, Paul, and Sharon Slade. 2016. 'Big Data, Higher Education and Learning Analytics: Beyond Justice, towards an Ethics of Care'. In Big Data and Learning Analytics in Higher Education: Current Theory and Practice, 109-24. Cham: Springer International Publishing. https://doi.org/10.1007/978-3-319-06520-5_8. 
Read, B, Louise Archer, and C Leathwood. 2003. 'Challenging Cultures? Student Conceptions of "Belonging" and "Isolation" at a Post-1992 University". Studies in Higher Education 28 (3): 261-77.

https://doi.org/10.1080/03075070309290\#.UlvbrBDwBB4.

Säljö, R. 2010. 'Digital Tools and Challenges to Institutional Traditions of Learning: Technologies, Social Memory and the Performative Nature of Learning'. Journal of Computer Assisted Learning 26 (1): 53-64. https://doi.org/10.1111/j.13652729.2009.00341.x.

Sánchez, R.A, V Cortijo, and U Javed. 2013. 'Students' Perceptions of Facebook for Academic Purposes'. Computers \& Education 70 (1): 138-49.

Seale, Jane. 2012. 'When Digital Capital Is Not Enough: Reconsidering the Digital Lives of Disabled University Students'. Learning, Media and Technology, no. August: 1-14. https://doi.org/10.1080/17439884.2012.670644.

Selwyn, N. 2014. Digital Technology and the Contemporary University: Degrees of Digitization. Abingdon, Oxfordshire: Routledge.

—. 2016. 'Digital Downsides: Exploring University Students' Negative Engagements with Digital Technology'. Teaching in Higher Education 21 (8): 1006-21. https://doi.org/10.1080/13562517.2016.1213229.

Smith, J., Z. Skbris, and M. Western. 2013. 'Beneath the "Digital Native" Myth"'. Journal of Sociology 49 (1): 97-118.

Thomas, Liz. 2002. 'Student Retention in Higher Education: The Role of Institutional Habitus'. Journal of Education Policy 17 (4): 423-42. https://doi.org/10.1080/02680930210140257. 
Time of Change: Final Report from the What Works? Student Retention and Success Programme.' York, UK.

Urrieta, Luis. 2007. 'Identity Production in Figured Worlds: How Some Mexican Americans Become Chicana/o Activist Educators'. Urban Review 39 (2): 117-44. https://doi.org/10.1007/s11256-007-0050-1.

Vygotsky, Lev Semenovich, and A Kozulin. 1986. Thought and Language. Cambridge, Massachusetts: MIT press. 
Figure 1. Extract from Evernote documentary showing a Skype mentoring conversation.

\section{2/11/13 Skype Work Session}

I regularly Skype my friend studying at a different university to have work/revision session. While we both do different subjects we try and prepare something to teach each other as a way of revising. We also spend a good part of our conversation talking about life at university etc as she is in her final year she is really good at providing advice and support.

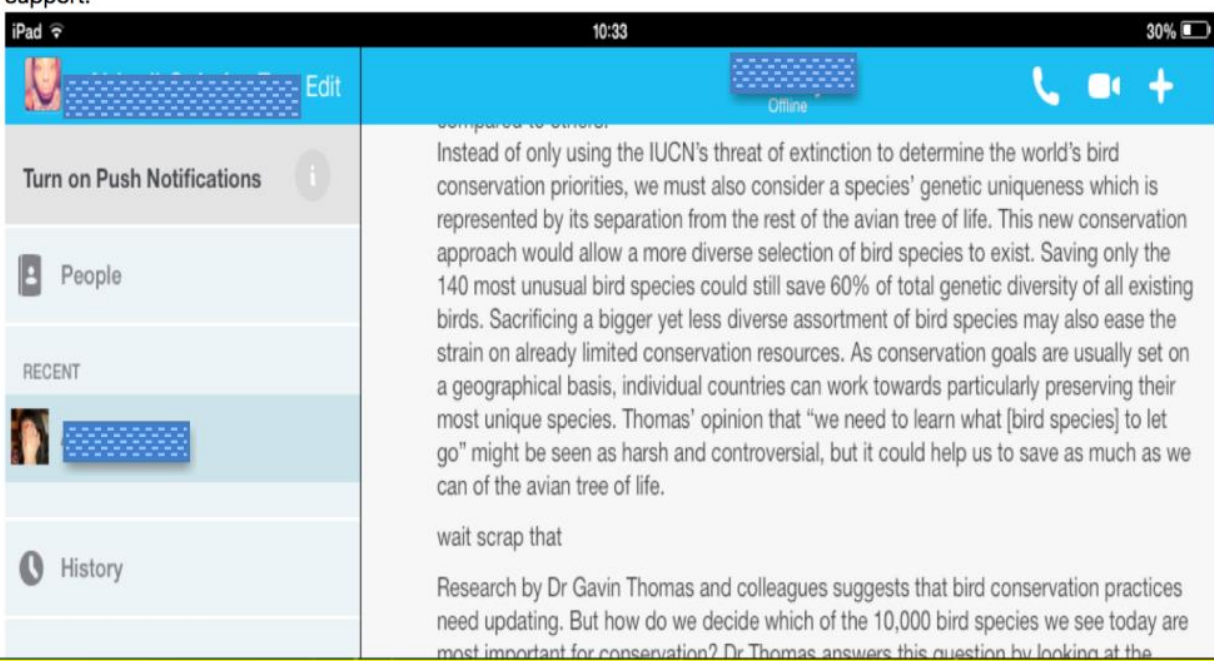


Table 1

\begin{tabular}{|c|c|c|c|c|c|c|}
\hline $\begin{array}{c}\text { Age } \\
\text { group }\end{array}$ & \multicolumn{2}{|l|}{ Ethnic background } & \multicolumn{2}{c|}{ Gender } & \multicolumn{2}{c|}{ Location } \\
\hline British & BAME & $\begin{array}{c}\text { White } \\
\text { Bromale }\end{array}$ & Female & $\begin{array}{c}\text { Local } \\
\text { (own/family } \\
\text { home) }\end{array}$ & $\begin{array}{c}\text { Campus- } \\
\text { based }\end{array}$ \\
\hline $\begin{array}{c}\text { Mature } \\
\text { Students } \\
\text { (over 21) }\end{array}$ & 2 & 9 & 6 & 5 & 7 & 4 \\
\hline $\begin{array}{c}\text { Direct } \\
\text { Entrants } \\
(18-21)\end{array}$ & 9 & 11 & 11 & 9 & 0 & 20 \\
\hline & $\mathbf{1 1}$ & $\mathbf{2 0}$ & $\mathbf{1 7}$ & $\mathbf{1 4}$ & $\mathbf{7}$ & $\mathbf{2 4}$ \\
\hline
\end{tabular}

Table 1: [name removed] Study: Intersecting widening participation indicators (self identified from initial survey) 